\title{
Expression profiling of adhesion proteins during prenatal and postnatal liver development in rats
}

This article was published in the following Dove Press journal:

Stem Cells and Cloning:Advances and Applications

20 September 2017

Number of times this article has been viewed

\section{Mehwish Yousaf' \\ Asima Tayyeb ${ }^{2}$ \\ Gibran Ali'}

'National Centre of Excellence in Molecular Biology, University of the Punjab, ${ }^{2}$ School of Biological Sciences, University of the Punjab, Lahore, Pakistan
Correspondence: Gibran Ali National Centre of Excellence in Molecular Biology, Lahore 54000, Pakistan

Tel +92 4238777947

Email g.ali@cemb.edu.pk

\begin{abstract}
Culturing of primary hepatocytes and stem cell-derived hepatocytes faces a major issue of dedifferentiation due to absence of cell-cell adhesion and 3D structures. One of the possible ways to eliminate the problem of dedifferentiation is mimicking the expression pattern of adhesion proteins during the normal developmental process of liver cells. The purpose of this study was to evaluate the expression pattern of some key adhesion proteins, namely, E-cadherin, N-cadherin, epithelial CAM (EpCAM), intracellular CAM (ICAM), collagen $1 \alpha 1, \alpha$-actinin, $\beta$-catenin and vimentin, in the liver tissue during prenatal and postnatal stages. Furthermore, differences in their expression between prenatal, early postnatal and adult stages were highlighted. Wistar rats were used to isolate livers at prenatal Day 14 and 17 as well as on postnatal Day 1, 3, 7 and 14. The liver from adult rats was used as control. Both conventional and real-time quantitative polymerase chain reactions (PCRs) were performed. For most of the adhesion proteins such as E-cadherin, N-cadherin, EpCAM, ICAM, collagen $1 \alpha 1$ and $\alpha$-actinin, low expression was observed around prenatal Day 14 and an increasing expression was observed in the postnatal period. Moreover, $\beta$-catenin and vimentin showed higher expression in the early prenatal period, which decreased gradually in the postnatal period, but still this low expression was considerably higher than that in the adult control rats. This basic knowledge of the regulation of expression of adhesion proteins during different developmental stages indicates their vital role in liver development. This pattern can be further studied and imitated under in vitro conditions to achieve better cell-cell interactions.
\end{abstract}

Keywords: CAMS, cadherins, embryonic, hepatic

\section{Introduction}

Several liver diseases such as viral hepatitis, fatty liver disease, hepatic carcinoma and liver cirrhosis can cause chronic or acute liver failure. Surgical complications associated with liver transplantation and limited donor availability have shifted the major therapeutic approach toward the use of stem cells. ${ }^{1}$ Stem cells have potential for a number of applications in the biomedical field, including cell replacement for repair of damaged organs, as an in vitro source of drug testing and as a tool for studying genetic defects. ${ }^{2}$ Stem cells are a very attractive source for cell replacement therapy in liver diseases as they can differentiate into hepatocyte-like cells (HLCs) in vitro. ${ }^{3}$ HLCs can be derived from induced pluripotent stem cells (iPSCs), ${ }^{4}$ hepatic progenitor cells (HPCs), ${ }^{5}$ embryonic stem cells (ESCs) ${ }^{6}$ and mesenchymal stem cells (MSCs). ${ }^{7}$

A challenge that confronts all primary and stem cell-derived cell cultures is maintaining a mature cell phenotype. The life span of HLCs and primary hepatocytes is 
usually limited, and they progressively lose their liver-specific functions in cultures, a process known as dedifferentiation. ${ }^{89}$ Moreover, liver perfusion and culturing practices destroy the normal tissue architecture and cell junctions between adjacent cells of hepatocytes, as well as resulting in loss of normal cell polarity. ${ }^{10}$ This renders these cultures ineffective for various protocols such as drug testing, because for these applications, a stable liver-specific culture comparable to the in vivo conditions is needed. The main reason behind this problem is the absence of both cell-cell adhesion and 3D matrices to which cells can adhere. Conventional approaches to overcome this difficulty include the addition of differentiation-promoting compounds to the culture medium, reintroduction of the extracellular matrix (ECM) or cocultivation of hepatocytes with other cell types. ${ }^{11}$ Currently, different biomaterials, such as collagen and Matrigel layers, ${ }^{12}$ fibroblast feeder layer cultures and nanofiber scaffolds, ${ }^{7}$ are used to maintain stable cell adhesive properties. Despite their advantages, these methods cannot provide complex cell adhesions present in vivo and exhibit low cell density/functional capacity per unit volume. ${ }^{13}$ Therefore, there is a need to analyze the temporal and spatial expression patterns of cell adhesion proteins during embryonic liver development to mimic them in the early stages of hepatic differentiation during in vitro culture.

Cell-cell interactions among different cell types of fetal liver are essential for the development of functional lobules. ${ }^{14} \mathrm{CAMs}$ are specialized integral membrane proteins for cell-cell adhesion in tissues. CAMs can be organized in the form of dense clusters to create specialized junctions such as adherens, tight and gap junctions. ${ }^{15}$ The most important class of CAMs is the cadherins, which are $\mathrm{Ca}^{2+}$-dependent transmembrane proteins involved in hemophilic cell-cell adhesion. The other important class of CAMs is the immunoglobulin (Ig)-like superfamily, which provides $\mathrm{Ca}^{2+}$-independent cell-cell adhesion. It includes intracellular CAMs (ICAMs), which are mainly present on the endothelial cell surface and function as signaling molecules for the attachment of cytotoxic T-lymphocytes (CTLs) and natural killer (NK) cells, in addition to providing leukocyte-endothelial cell adhesion. ${ }^{16}$ All these adhesion molecules are collectively responsible for the smooth control of cell motility, cell shape and tissue organization. The timing of expression of these molecules in the prenatal and postnatal phases is important, as many of these proteins also regulate signaling functions during developmental stages. ${ }^{10}$

The aim of the current study is to evaluate the regulation of expression of key adhesion proteins and their differences in the prenatal, early postnatal and adult stages. This may provide key information about when and how much of these proteins can be used in HLC cultures to imitate the early developmental process and obtain a stable culture.

\section{Animals and methods}

\section{Animals}

The current study was carried out on almost 6 months old Wistar rats. The animals were kept in an animal house under pathogen-free controlled climate conditions (temperature $22^{\circ} \mathrm{C}$ ) and 12-hour light/dark cycle. Ad libitum access to standard rodent chow and water was provided. All the experimental procedures were approved by the Committee of Animal Care, National Center of Excellence in Molecular Biology, University of the Punjab, Lahore, Pakistan. The investigation conforms to the Guidelines for the Care and Use of Laboratory Animals published by the US National Institutes of Health (NIH Publication No 85-23, revised 1985).

\section{Experimental design}

Liver sample collection was done at two phases, namely, the prenatal phase and postnatal phase. Prenatal sampling was done at Day 14 and Day 17 of gestation. Postnatal sampling was done at days 1, 3, 7 and 14 after birth. The detailed scheme is shown in Table 1.

\section{Liver isolation at prenatal and postnatal stages}

Male and female rats were paired in the evening and on the next morning, female rats were observed for vaginal plugs. The presence of the plug indicated mating, and that day was designated as the 0.5 th day postcoitum (dpc). On the specific days of liver isolation, female rats were euthanized, and the fetuses were removed by cutting the uterus lining. The fetus was further dissected under a microscope using a 10× objective lens to isolate the liver. For the isolation of the postnatal liver, rat pups were dissected. Excised livers were washed with PBS (Thermo Fisher Scientific, Waltham, MA, USA) twice to remove extra blood. A part of the liver (almost $2 \mathrm{mg}$ )

Table I Experimental groups indicated by days and abbreviations

\begin{tabular}{lll}
\hline Groups & Time interval & Abbreviation \\
\hline \multirow{2}{*}{ Prenatal } & Day I4 & FI4 \\
& Day I7 & FI7 \\
& Day I & NI \\
Postnatal & Day 3 & N3 \\
& Day 7 & N7 \\
Adult rat & Day I4 & NI4 \\
\hline
\end{tabular}

Abbreviations: $\mathrm{F}$, fetal; $\mathrm{N}$, neonatal. 


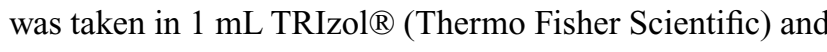
used for RNA extraction.

\section{Gene expression profiling}

After careful isolation of the rat livers on the specific prenatal and postnatal days, gene expression profiling for the adhesive proteins was performed using both conventional polymerase chain reaction (PCR) and real-time quantitative PCR (qPCR).

Total RNA was extracted from all experimental groups by using TRIzol reagent according to the manufacturer's instructions. RNA was quantified using a spectrophotometer (ND-1000; Nanodrop Technologies, Wilmington, DE, USA). The extracted RNA was stored at $-70^{\circ} \mathrm{C}$ until further use. cDNA was synthesized from total RNA by using the Moloney murine leukemia virus (M-MLV) reverse transcriptase cDNA synthesis kit (Thermo Fisher Scientific) and stored at $-20^{\circ} \mathrm{C}$. Reverse transcription (RT)-PCR was performed for various adhesion proteins. cDNA was amplified against specific genes by using Taq polymerase kit (Thermo Fisher Scientific). Amplified products were electrophoresed on 2\% agarose gel (Sigma-Aldrich, St Louis, MO, USA) containing $0.5 \mu \mathrm{g} / \mathrm{mL}$ ethidium bromide (Sigma-Aldrich). Gel bands were analyzed using the GelDoc system (Benchtop UV Transilluminator, Syngene Ingenius, UK).

Furthermore, real-time RT-PCR was carried out for the quantitative analysis of gene expression using Maxima SYBR Green/ROX qPCR Master Mix (2×) (Thermo Fisher Scientific). Samples were run in triplicate. Data acquisition was performed during the extension step. Comparative cycle threshold method ( $\Delta \mathrm{Ct}$ value) was used for the relative quantification of target genes. $\beta$-actin was used as an internal control. The primer sequences used for both qualitative and quantitative expression analyses of the relevant genes, along with their annealing temperatures, are given in Table 2.

\section{Statistical analysis}

All values are presented as mean value \pm SD. Significant differences between the experimental groups were determined by using repeated-measures (RM) one-way analysis of variance (ANOVA) using GraphPad Prism software. Statistical significance was considered at $P \leq 0.05$.

\section{Results and discussion}

The assembly of different types of cells into tissues leading to organs requires molecular interactions at the cellular level. These molecular interactions are achieved by a wide array of temporally and spatially regulated adhesion proteins. These adhesion proteins also play a decisive role in hepatic morphogenesis during development. ${ }^{17}$ In the present study, we aimed to evaluate the expression of important adhesion proteins in the liver at the prenatal stages as well as in the early postnatal period in rats.

The most crucial CAMs responsible for cell-cell adhesion are the cadherins. E-cadherin and N-cadherin showed similar expression patterns. Expression was low in the early prenatal stage F14, which gradually increased until the late postnatal stage N14. Reduced expression could be observed in the adult control (A) for both genes (Figure 1). E-cadherin is a

Table 2 Primer sequences and optimized annealing temperatures for the genes used for expression analysis

\begin{tabular}{|c|c|c|c|}
\hline Genes & $5^{\prime}-3^{\prime}$ sequence & Annealing temperature, ${ }^{\circ} \mathrm{C}$ & Product size, base pairs \\
\hline$\alpha-\operatorname{Actinin}(F)$ & AACAGCAGCCAATCGAATCT & \multirow{2}{*}{59} & \multirow{2}{*}{195} \\
\hline$\alpha$-Actinin (R) & CGTCGGTAGTCTCGGAAGTC & & \\
\hline$\beta$-Catenin (F) & CTCTAGTGCAGCTTCTGGGTTCT & \multirow{2}{*}{63} & \multirow{2}{*}{172} \\
\hline$\beta$-Catenin (R) & GTAATGTCCTCCCTGTCACCA & & \\
\hline E-cadherin $(F)$ & TGAGAAGACAGAAACGAGACTGG & \multirow{2}{*}{59} & \multirow{2}{*}{177} \\
\hline E-cadherin $(\mathrm{R})$ & ATGATGAAAACGCCAACAGG & & \\
\hline $\operatorname{EpCAM}(\mathrm{F})$ & TGAGAATGGTGAATGCCAGT & \multirow{2}{*}{63} & \multirow{2}{*}{180} \\
\hline EPCAM (R) & TCGTCACACTCGGGATCATA & & \\
\hline ICAM (F) & ACACGGTCTTACTTTGCCATTT & \multirow{2}{*}{61} & \multirow{2}{*}{222} \\
\hline ICAM (R) & GTCTGGTTCTTCAGGGTCTCTCT & & \\
\hline$N$-cadherin $(F)$ & TCAGTATGAAAGCAGTGAACCAG & \multirow{2}{*}{63} & \multirow{2}{*}{240} \\
\hline $\mathrm{N}$-cadherin $(\mathrm{R})$ & CTGGCGAGTTGTCTAGGGAATAC & & \\
\hline Collagen-I $\alpha \mid(F)$ & TGAGTCAGCAGATTGAGAAC & \multirow{2}{*}{57} & \multirow{2}{*}{301} \\
\hline Collagen- $|\alpha|(R)$ & TACTCGAACGGGAATCCATC & & \\
\hline Vimentin (F) & CGGCTGCGAGAGAAATTGC & \multirow{2}{*}{59} & \multirow{2}{*}{123} \\
\hline Vimentin (R) & CCACTTTCCGTTCAAGGTCAAG & & \\
\hline$\beta$-Actin (F) & GCTGTGTTGTCCCTGTATGC & \multirow{2}{*}{57} & \multirow{2}{*}{102} \\
\hline$\beta$-Actin (R) & GAGCGCGTAACCCTCATAGA & & \\
\hline
\end{tabular}

Abbreviations: $F$, forward primer; $R$, reverse primer. 


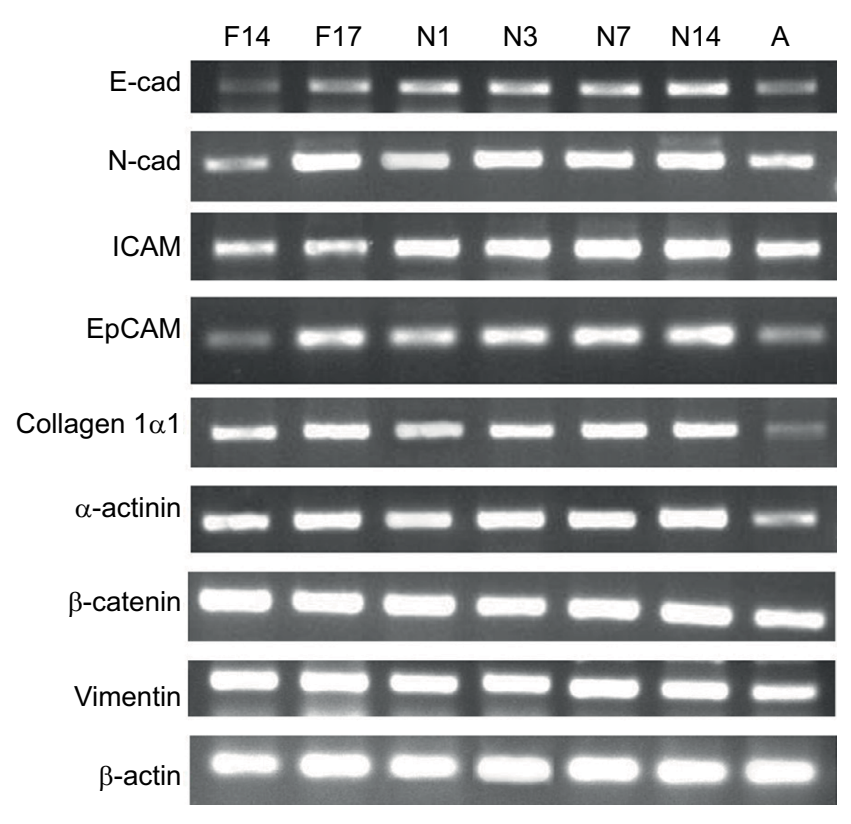

Figure I Expression of selected genes at different prenatal and postnatal stages observed through gel electrophoresis.

Notes: The difference in the width and brightness of band indicates the change in expression level. $\beta$-actin was used as an internal control. FI4 and FI7 are prenatal days, where $\mathrm{F}$ indicates fetus. The designators NI-NI4 denote the postnatal days, where $\mathrm{N}$ indicates neonatal. Adult sample (coded as $\mathrm{A}$ ) was used as control.

Abbreviations: E-cad, E-cadherin, ICAM, intracellular CAM; N-cad, N-cadherin.

transmembrane protein, majorly involved in $\mathrm{Ca}^{2+}$-dependent cell-cell adhesions. It is found most abundantly in adherens junctions and it ensures the integrity of epithelial tissues in the liver. ${ }^{18}$ In the present study, low expression of E-cadherin was observed on prenatal Day 14 ( $0.5 \pm 0.14$ fold $)$, which doubled on the prenatal Day 17 (Figure 2A). Shiojiri and Sugiyama ${ }^{19}$ previously reported high expression of E-cadherin in biliary epithelial cells (BECs).This justifies the considerably low expression observed at prenatal Day 14, around which time the hepatoblasts are reported to start differentiating into hepatocytes and BECs. ${ }^{17}$ As the population of BECs and hepatocytes increases, an increase in E-cadherin expression could be observed. Expression of E-cadherin increased steadily throughout the postnatal period and reached 1.6 \pm 0.11 fold level at postnatal Day 14. As the postnatal period is the phase of extensive liver growth, this increase in expression indicates the active role of E-cadherin in the proliferation of hepatocytes and maintenance of the tissue architecture.

Neural or $\mathrm{N}$-cadherin is another $\mathrm{Ca}^{2+}$-dependent cadherin, involved in heterotypic cell-cell adhesion. ${ }^{20}$ It was originally identified as a CAM in the neural tissues, but it has been shown to be expressed in various nonneural tissues including the liver. ${ }^{21} \mathrm{~N}$-cadherin participates in multiple signal transduction events, including cell survival, cell motility and morphological transformation. ${ }^{22} \mathrm{~N}$-cadherin showed a similar expression pattern as E-cadherin in different groups. $\mathrm{N}$-cadherin expression on the prenatal Day 14 was $0.4 \pm 0.09$ fold less than that in the adult control. Afterward, the expression increased significantly on prenatal Day 17 , ie, by $2.4 \pm 0.50$ fold, and almost remained the same in the postnatal period, up to Day 3. Later groups showed further increase in the expression, reaching 3.5 \pm 0.16 fold at postnatal Day 14 (Figure 2B). The expression abruptly increased between F14 and $\mathrm{F} 17$, indicating the role of $\mathrm{N}$-cadherin in the later stages of embryonic liver development. In previous studies, expression of N-cadherin has also been reported to be important for the differentiation of hepatoblasts into hepatocytes and BECs..$^{21}$ Throughout the postnatal period, an increase in the expression of $\mathrm{N}$-cadherin was observed, indicating its key role in liver growth. It was also observed that expression of N-cadherin was significantly higher than the expression of E-cadherin. It is possible that both these cadherins are expressed in separate compartments or cells of the liver tissue, but as we have taken the whole tissue sample for qPCR, this could not be determined without immunostaining of the liver tissue sections.

ICAM is expressed on the endothelial cells and is responsible for inflammatory cell recruitment and activation by mediating leukocyte-endothelial cell adhesion. ${ }^{23}$ The expression of ICAM on the prenatal days 14 and 17 was $0.34 \pm 0.07$ and $0.44 \pm 0.11$ fold lower than that in the adult control. However, its expression markedly increased readily after birth on postnatal Day 1 . The expression gradually increased in the postnatal period, and the highest expression was observed on postnatal Day 14 , ie, $2.74 \pm 0.11$ fold higher than that in the adult control (Figure 2C). Opposite of this expression pattern was observed by Sugiyama et al, ${ }^{24}$ wherein peak expression was seen at embryonic Day 12 and no expression was seen in the postnatal stage. However, Attar et $\mathrm{a}^{25}$ reported the same pattern of change of expression, namely, lower in early development and higher in neonatal stage, during the lung development. ICAM is expressed constitutively on all endothelial cells; therefore, as the mass of the liver increases, a surge in the expression of ICAM can be observed. It has also been reported that in young fetal mouse livers, the major cells responsible for ICAM expression are hepatoblasts, whose expression of both cell adhesion molecules is in good agreement with the timing of hepatic hemopoiesis, suggesting that ICAM may be involved in some step of hepatic hemopoiesis. ${ }^{26,27}$

Expression analysis was also carried out for epithelial CAM (EpCAM), a type 1 transmembrane glycoprotein, reported to be involved in cell adhesion by binding 

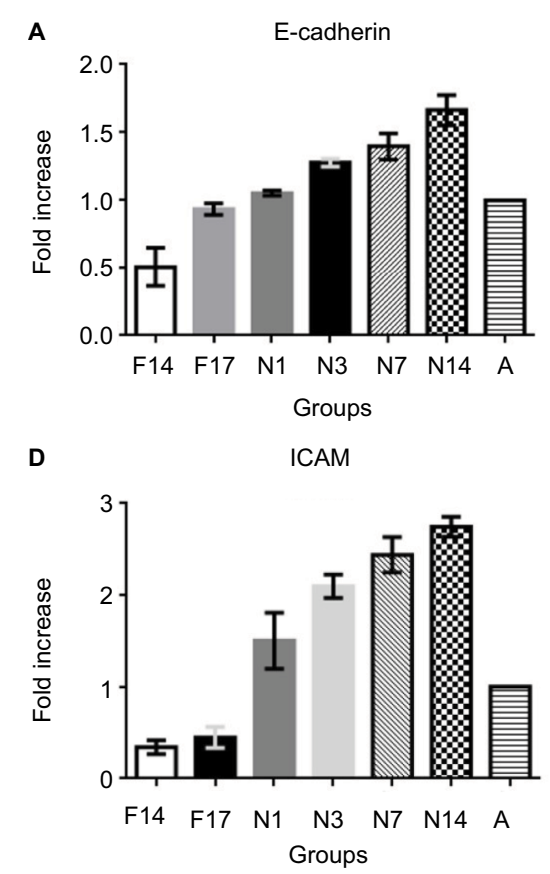

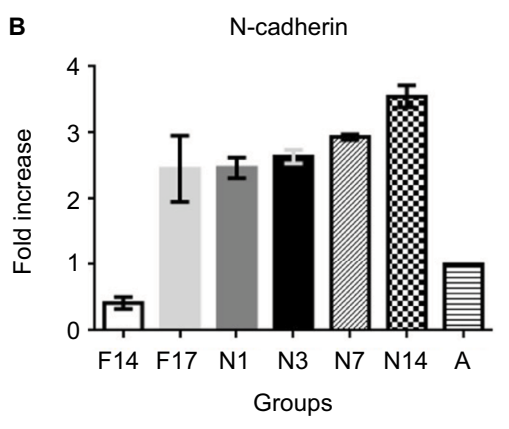

E

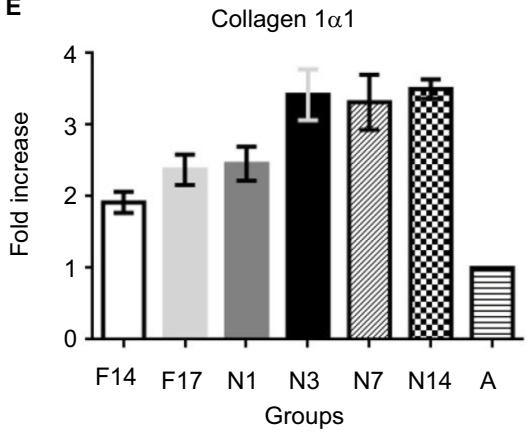

C

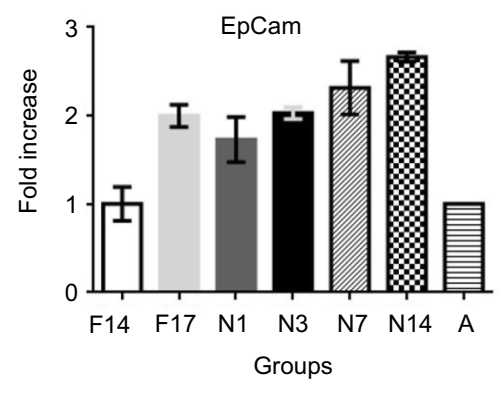

$\mathbf{F}$

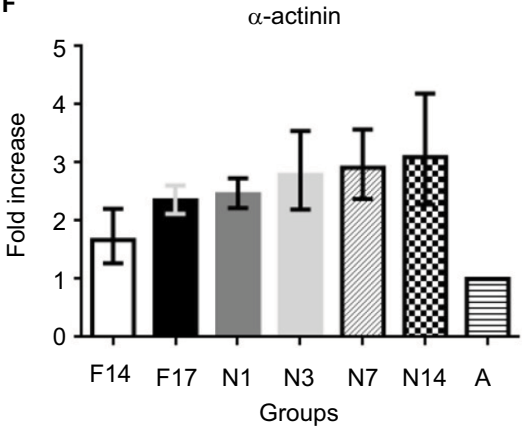

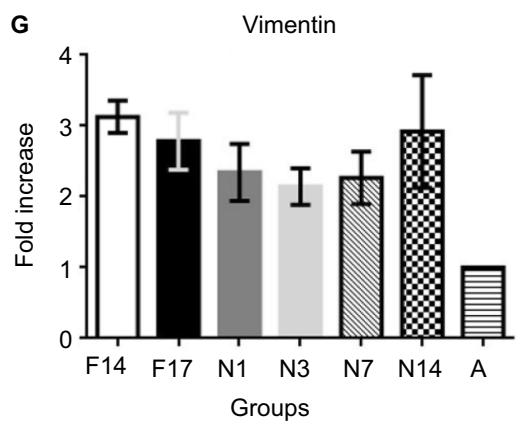

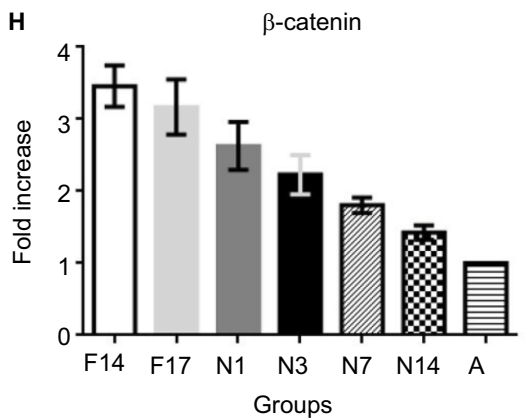

Figure 2 Real-time PCR analysis of selected genes at different prenatal and postnatal stages.

Notes: Fold increase in the expression of all selected genes is observed. (A) E-cadherin, (B) N-cadherin, (C) EpCAM, (D) ICAM, (E) collagen I $\alpha$ I, (F) $\alpha$-actinin, (G) vimentin and $(\mathbf{H}) \beta$-catenin. Values are expressed as mean value $\pm S D$. $* *$-value was statistically significant $(P \leq 0.05)$. FI4 and FI7 are prenatal days, where $F$ indicates fetus. The designators NI-NI4 denote the postnatal days, where $\mathrm{N}$ indicates neonatal. Adult sample (coded as $\mathrm{A}$ ) was used as control.

Abbreviations: ICAM, intracellular CAM; PCR, polymerase chain reaction.

$\alpha$-actinin. ${ }^{28}$ EpCAM gene showed same expression at the prenatal Day 14 as the adult control $(1.00 \pm 0.19)$, which doubled at the prenatal Day $17(1.99 \pm 0.12)$. A slight decrease in the expression was observed after birth at postnatal Day 1 , which gradually increased in later postnatal days. The highest expression of $2.66 \pm 0.05$ fold was observed in postnatal Day 14 (Figure 2D). Studies have shown that EpCAM is majorly expressed in the epithelia of bile ducts (novel hepatic). This explains the increasing expression of EpCAM after prenatal Day 14 because of the biliary commitment of some hepatoblasts and formation of intrahepatic bile ducts. However, the finding of EpCAM's considerable expression at prenatal Day 14 also confirms that hepatoblasts also express EpCAM. No study explains the behavior of EpCAM in the postnatal phase. It can be observed from the qPCR results that EpCAM expression gradually increases in the postnatal days. Although no concrete conclusion can be drawn from this observation, the possible role of EpCAM in hepatic growth and maturation can be speculated. Moreover, in the adult liver, reduced expression of EpCAM was observed. EpCAM is involved in oval cell migration and is considered an early biomarker of hepatocellular carcinoma (HCC); the low expression in the normal adult liver is expected unless acted upon by liver injury. ${ }^{29}$

Collagen I $\alpha 1$ is a fibrillar type of collagen that provides mechanical strength and resilience to the ECM. ${ }^{30}$ Our data indicate that collagen I $\alpha 1$ is expressed very early in the embryonic development of liver. Liver samples at prenatal Day 14 showed high expression of collagen $I \alpha 1$, which further increased up to prenatal Day 17. Expression of collagen $1 \alpha 1$ was almost $1.91 \pm 0.14$ fold higher on the prenatal Day 14 compared to that in the adult control. The expression 
further increased up to prenatal Day 17 and remained almost the same after birth at postnatal Day 1. The expression markedly increased on postnatal Day 3 (3.42 \pm 0.35 fold) and remained high throughout the later postnatal days (Figure $2 \mathrm{E})$. As collagen is the most abundant protein of the ECM, its higher concentration is expected during development for the establishment of tissue architecture. This higher expression was retained after birth and it peaked on the postnatal Day 3 , indicating the need for collagen I $\alpha 1$ during the increase in the liver size to provide scaffold for the cells. However, once the proper liver size is achieved, as in adult control, the collagen I $\alpha 1$ expression markedly reduces. There is no need for the highly active mRNA expression of collagen I $\alpha 1$ in adults, unless faced by liver injury or fibrosis.

$\alpha$-actinin is an actin-binding protein of the cytoskeleton that maintains the cell shape and provides mechanical stability to the cell. ${ }^{31} \mathrm{~A}$ gradual increase in the $\alpha$-actinin expression was observed with the increasing time of the developmental stages. The lowest expression was observed at the prenatal Day 14 and the highest was at the postnatal Day 14, ie, $1.68 \pm 0.18$ fold and $3.11 \pm 0.39$ fold, respectively (Figure $2 \mathrm{~F}$ ). Because of the role of $\alpha$-actinin in tissue structure formation, its expression initiates with the start of embryonic liver development. With increasing size of liver bud and liver mass, increased $\alpha$-actinin expression is observed. However, in adult liver, it is reduced because the liver has achieved its normal size, and active mRNAs of $\alpha$-actinin are not present in abundance. There is no previous report available describing the change of expression of $\alpha$-actinin in the postnatal period. Therefore, there is need for further detailed analysis of $\alpha$-actinin expression at the cellular level in the postnatal phase.

Vimentin is also a tissue architectural protein, a member of type III intermediate filaments, involved in maintenance of cell shape and motility. ${ }^{32}$ In the present study, vimentin gene expression was $3.13 \pm 0.22$ fold on the prenatal Day 14 and it decreased gradually to $2.14 \pm 0.25$ fold on postnatal Day 3. Later on, the expression again increased up to $2.92 \pm 0.79$ fold, compared to the control, on the postnatal Day 14 (Figure 2G). Even this reduced expression was considerably high compared to that in the adult control rats. It has also been reported that vimentin expression starts commencing around embryonic Day 8.5, whereas in adults, the vimentin expression is limited and temporal. ${ }^{33}$ This study has revealed a similar pattern of vimentin expression during postnatal liver development. Further investigations to explain this pattern of expression are required. However, this high expression throughout the developmental process clearly indicates that vimentin is a key regulator in early tissue formation and maintenance of architecture in late postnatal stages.

A very high expression of $\beta$-catenin, a cytosolic cell adhesion protein, was observed at the prenatal Day $14(3.45 \pm 0.28$ fold) compared to the adult control, which became reduced at the prenatal Day 17. Its expression starts to reduce gradually during the postnatal period. However, the expression in the postnatal period remained higher than that in the adult control (Figure 2H). This finding coincides with previous studies that reported the same pattern of $\beta$-catenin expression during embryonic development. ${ }^{34,35}$ The higher expression in early stages of liver development is because of the important role of $\beta$-catenin in liver bud growth through the expansion of hepatoblasts. ${ }^{34}$ Temporal signaling of $\mathrm{Wnt} / \beta$-catenin is also important in the hepatoblast differentiation and hepatocyte maturation. ${ }^{36} \mathrm{~A}$ gradual decrease in the $\beta$-catenin expression was observed in the postnatal period. Even though the expression was decreased, it remained significantly high compared to that in the adult control. The high expression of $\beta$-catenin is responsible for the surge of cell proliferation in the postnatal stage. Apte et $\mathrm{al}^{37}$ reported a surge in $\beta$-catenin activity during postnatal days $0-20$ in mouse models. They also indicated that $\beta$-catenin-knockout mouse shows reduced liver size at postnatal Day $30 .{ }^{37}$

A general pattern that can be seen for most of the adhesion proteins, with few exceptions, is that they are expressed in high concentration in early liver development as well as in the postnatal stage. Because both prenatal and postnatal stages correspond to immense cell proliferation and tissue development, these proteins bind cells together to maintain a true tissue shape and structure. Once proper liver size is achieved in the normal adult liver, these proteins' active mRNAs are expressed in lower concentrations. Moreover, increased concentrations of these proteins in adult livers are an indication of several melanomas and thus used as hepatocarcinogenic markers. ${ }^{38,39}$

\section{Conclusion}

All the observations presented in this study provide basic knowledge of the pattern of changes in adhesive proteins during different developmental stages. This pattern can be imitated under in vitro conditions to achieve better tissue interactions. However, more in-depth studies are needed to comprehend their exact role in hepatic development.

\section{Disclosure}

The authors report no conflicts of interest in this work. 


\section{References}

1. Duan B-W, Lu S-C, Wang M-L, et al. Liver transplantation in acuteon-chronic liver failure patients with high model for end-stage liver disease (MELD) scores: a single center experience of 100 consecutive cases. J Surg Res. 2013;183(2):936-943.

2. $\mathrm{Hu} \mathrm{C}, \mathrm{Li} \mathrm{L}$. In vitro culture of isolated primary hepatocytes and stem cell-derived hepatocyte-like cells for liver regeneration. Protein Cell. 2015;6(8):562-574.

3. Sancho-Bru P, Najimi M, Caruso M, et al. Stem and progenitor cells for liver repopulation: can we standardize the process from bench to bedside? Gut. 2009;58(4):594-603.

4. Amimoto N, Mizumoto H, Nakazawa K, Ijima H, Funatsu K, Kajiwara $\mathrm{T}$. Hepatic differentiation of mouse embryonic stem cells and induced pluripotent stem cells during organoid formation in hollow fibers. Tissue Eng Part A. 2011;17(15-16):2071-2078.

5. Wang Y, Cui CB, Yamauchi M, et al. Lineage restriction of human hepatic stem cells to mature fates is made efficient by tissue-specific biomatrix scaffolds. Hepatology. 2011;53(1):293-305.

6. Subramanian K, Owens DJ, Raju R, et al. Spheroid culture for enhanced differentiation of human embryonic stem cells to hepatocyte-like cells. Stem Cells Dev. 2013;23(2):124-131.

7. Piryaei A, Valojerdi MR, Shahsavani M, Baharvand H. Differentiation of bone marrow-derived mesenchymal stem cells into hepatocyte-like cells on nanofibers and their transplantation into a carbon tetrachloride-induced liver fibrosis model. Stem Cell Rev Rep. 2011;7(1): 103-118.

8. Papeleu P, Elaut G, Rogiers V, Vanhaecke T. Cell cultures as in vitro tools for biotransformation studies. In: Pandalai SG, editor. Recent Research Developments in Drug Metabolism and Disposition. India: Transworld Research Network; Vol. 1. 2002:199-234.

9. Wang K, Shindoh H, Inoue T, Horii I. Advantages of in vitro cytotoxicity testing by using primary rat hepatocytes in comparison with established cell lines. J Toxicol Sci. 2002;27(3):229-237.

10. Elaut G, Henkens T, Papeleu P, et al. Molecular mechanisms underlying the dedifferentiation process of isolated hepatocytes and their cultures. Curr Drug Metab. 2006;7(6):629-660.

11. Skardal A, Smith L, Bharadwaj S, Atala A, Soker S, Zhang Y. Tissue specific synthetic ECM hydrogels for 3-D in vitro maintenance of hepatocyte function. Biomaterials. 2012;33(18):4565-4575.

12. Kim Y, Rajagopalan P. 3D hepatic cultures simultaneously maintain primary hepatocyte and liver sinusoidal endothelial cell phenotypes. PLoS One. 2010;5(11):e15456.

13. Sellaro TL, Ranade A, Faulk DM, et al. Maintenance of human hepatocyte function in vitro by liver-derived extracellular matrix gels. Tissue Eng Part A. 2009;16(3):1075-1082.

14. Nitou M, Ishikawa K, Shiojiri N. Immunohistochemical analysis of development of desmin-positive hepatic stellate cells in mouse liver. $J$ Anat. 2000;197(pt 4):635-646.

15. Bilello J, Cable E, Myers R, Isom H. Role of paracellular junction complexes in baculovirus-mediated gene transfer to nondividing rat hepatocytes. Gene Ther. 2003;10(9):733-749.

16. Tachimori A, Yamada N, Sakate Y, et al. Upregulation of ICAM-1 gene expression inhibits tumour growth and liver metastasis in colorectal carcinoma. Eur J Cancer. 2005;41(12):1802-1810.

17. Lemaigre F, Zaret KS. Liver development update: new embryo models, cell lineage control, and morphogenesis. Curr Opin Genet Dev. 2004;14(5):582-590.

18. Young P, Boussadia O, Halfter H, et al. E-cadherin controls adherens junctions in the epidermis and the renewal of hair follicles. EMBO J. 2003;22(21):5723-5733.
19. Shiojiri N, Sugiyama Y. Immunolocalization of extracellular matrix components and integrins during mouse liver development. Hepatology. 2004;40(2):346-355.

20. Straub BK, Rickelt S, Zimbelmann R, et al. E-N-cadherin heterodimers define novel adherens junctions connecting endoderm-derived cells. J Cell Biol. 2011;195:873-887.

21. Gentanabe THA, Ozawa M. E-cadherin but not N-cadherin expression is correlated with the intracellular distribution of catenins in human hepatocellular carcinomas. Oncol Rep. 1998;5:1109-1114.

22. Nieman MT, Prudoff RS, Johnson KR, Wheelock MJ. N-cadherin promotes motility in human breast cancer cells regardless of their E-cadherin expression. J Cell Biol. 1999;147(3):631-644.

23. Dustin ML, Rothlein R, Bhan AK, Dinarello CA, Springer T. Induction by IL 1 and interferon-gamma: tissue distribution, biochemistry, and function of a natural adherence molecule (ICAM-1). J Immunol. 1986; 137:245-254.

24. Sugiyama Y, Koike T, Shiojiri N. Developmental changes of cell adhesion molecule expression in the fetal mouse liver. Anat Rec. 2010;293:1698-1710.

25. Attar MA, Bailie MB, Christensen PJ, Brocke TG, Wilcoxen SE, Paine R. Induction of ICAM-1 expression on alveolar epithelial cells during lung development in rats and humans. Exp Lung Res. 1999;25(3):245-259.

26. Tada T, Widayati D, Fukuta K. Morphological study of the transition of haematopoietic sites in the developing mouse during the peri-natal period. Anat Histol Embryol. 2006;35(4):235-240.

27. Kubota H, Yao HL, Reid LM. Identification and characterization of vitamin A storing cells in fetal liver: implications for functional importance of hepatic stellate cells in liver development and hematopoiesis. Stem Cells. 2007;25:2339-2349.

28. Balzar M, Winter M, De Boer C, Litvinov S. The biology of the 17-1A antigen (Ep-CAM). J Mol Med. 1999;77:699-712.

29. Kim JW, Ye Q, Forgues M, et al. Cancer-associated molecular signature in the tissue samples of patients with cirrhosis. Hepatology. 2004;39(2):518-527.

30. Elsharkawy A, Oakley F, Mann D. The role and regulation of hepatic stellate cell apoptosis in reversal of liver fibrosis. Apoptosis. 2005;10(5):927-939.

31. Gumbiner BM. Regulation of cadherin-mediated adhesion in morphogenesis. Nat Rev Mol Cell Biol. 2005;6(8):622-634.

32. Clarke EJ, Allan V. Intermediate filaments: vimentin moves in. Curr Biol. 2002;12(17):R596-R598.

33. Franke WW, Grund C, Kuhn C, Jackson BW, Illmensee K. Formation of cytoskeletal elements during mouse embryogenesis. Differentiation. 1982;23:43-59.

34. Micsenyi A, Tan X, Sneddon T, Luo J-H, Michalopoulos GK, Monga SP. $\beta$-Catenin is temporally regulated during normal liver development. Gastroenterology. 2004;126:1134-1146.

35. Lade AG, Monga SP. Beta-catenin signaling in hepatic development and progenitors: which way does the WNT blow? Dev Dyn. 2011;240(3):486-500.

36. Tan X, Yuan Y, Zeng G, et al. $\beta$-Catenin deletion in hepatoblasts disrupts hepatic morphogenesis and survival during mouse development. Hepatology. 2008;47:1667-1679.

37. Apte U, Zeng G, Thompson MD, et al. $\beta$-Catenin is critical for early postnatal liver growth. Am J Physiol Gastrointest Liver Physiol. 2007;292(6):G1578-G1585.

38. Nejak-Bowen K, Monga SP. Wnt/ $\beta$-catenin signaling in hepatic organogenesis. Organogenesis. 2008;4:92-99.

39. Tsubota A, Matsumoto K, Mogushi K, et al. IQGAP1 and vimentin are key regulator genes in naturally occurring hepatotumorigenesis induced by oxidative stress. Carcinogenesis. 2010;31(3):504-511. 
Stem Cells and Cloning: Advances and Applications is an international, peer-reviewed, open access journal. Areas of interest in stem cell research include: Embryonic cell stems; Adult stem cells; Blastocysts; Cordblood stem cells; Stem cell transformation and culture; Therapeutic cloning; Umbilical cord blood and bone marrow cells; Laboratory, animal and human therapeutic studies; Philosophical and ethical issues related to stem cell research. This journal is indexed on CAS. The manuscript management system is completely online and includes a quick and fair peer-review system. Visit http://www.dovepress.com/ testimonials.php to read real quotes from published authors..

Submit your manuscript here: https://www.dovepress.com/stem-cells-and-cloning-advances-and-applications-journal 